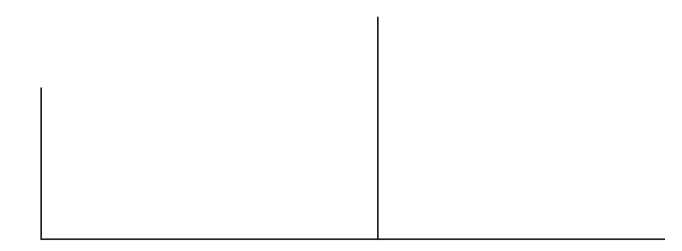

Rev. Latinoam. Psicopat. Fund., II, 2, 86-96

\title{
Observando o invisível: uma epistemologia psicanalítica
}

Andréa Linhares

Partindo da imagem da dissecação de cadáveres, considerada como "cena primitiva" da ciência moderna, o presente artigo propõe indicar uma especificidade da observação em psicanálise por meio do paradigma do sonho, espaço, não mais do visível, mas do visual e do alucinatório. Nesta configuração, a observação se encontra intrinsecamente ligada à experiência transferencial. A autora atenta, então, para os laços transferênciais que ligam pesquisador e objeto de estudo, numa analogía entre a investigação científica e a situação analítica.

Palavras-chave: Observação, sonho, transferência, psicanálise 


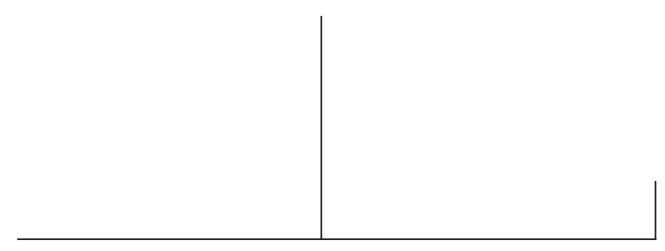

A tendência hegemônica com que se instituiu a ciência moderna pretendeu propor conhecimentos e uma metodologia idealmente esvaziada de toda subjetividade. A imagem da dissecação de cadáveres, paradigmática desta concepção de conhecimento, promoveu um objeto de estudo demonstrável e universal, associando a referência ao "visível" à idéia de objetivação.

Essa referência ao olhar será o fio condutor a partir do qual desenvolveremos algumas reflexões sobre as especificidades da pesquisa em psicanálise, numa comparação com o lugar da visão, em outros campos do saber.

Evoquemos A lição de anatomia ${ }^{1}$, de Rembrandt, como uma alegoria da observação científica, onde homens da ciência se debruçam sobre uma "coisa" inerte, muda, exposta. De um lado, o objeto de investigação: um corpo morto; do outro, um pensamento vivo que disseca e observa. O sujeito observador e seu objeto de estudo se encontram assim partidos, radicalmente opostos quanto à matéria constituinte de sua própria natureza.

O objeto científico aparece então como externo ao observador, e este distanciamento, que funciona como uma clivagem entre observador e objeto, conferiria à observação o ideal da assepsia científica. A observação, então solidária a uma simples constatação, se assemelharia a uma experiência esvaziada de toda subjetividade.

Mesmo sabendo que Freud sempre reivindicou a cientificidade da psicanálise, posicionando-se, de alguma forma, como herdeiro do positivismo, não podemos desconhecer que o nascimento da psicanálise se funda numa filiação feita de rupturas. Rupturas que dizem respeito às vias de acesso ao conhecimento e, conseqüentemente, à relação entre o sujeito-observador e seu

1. Trata-se de um dos quadros mais famosos de Rembrandt: A lição de anatomia do Dr. Tup, pintado em 1632, provocando dezenas de encomendas de retratos em grupos. Este quadro pertence ao acervo do Museu Rijnmuseum de Amsterdam. 


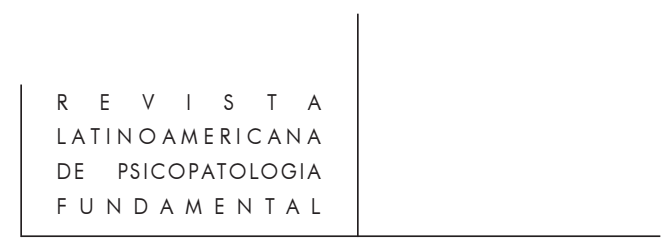

objeto de estudo. O objeto da ciência tradicional, ilustrado por Rembrandt, aparece como visível, dissecável e externo ao observador, enquanto a psicanálise nos oferece um objeto que só pode ser apreendido através e a partir da subjetividade do observador. A originalidade marcante da psicanálise reside no fato de que, de certa forma, o observador é, ele mesmo, o seu objeto de estudo: transferência e contratransferência são as únicas vias de acesso ao conhecimento. Como indica Sophie de Mijolla:

existe uma especificidade intransferível que todo pesquisador experimenta quando compreende que o vínculo teórico-clínico sobre o qual trabalha é, antes de mais nada, feito da matéria mesma da sua própria contratransferência, e que é a partir da revivescência dos seus próprios afetos que ele pode escutar o seu paciente. ${ }^{2}$

Esta singularidade atravessa todos os pontos da psicanálise, começando mesmo pela sua história, cujo nascimento se confunde com a história do seu fundador, no que ela tem de mais íntimo.

Se a imagem da dissecação de cadáveres poderia representar de uma certa maneira a "cena primitiva" da ciência moderna, o que a psicanálise vai promover é uma espécie de descentramento do foco de interesse desta cena. Contrariamente às ciências anatômicas que, nesta imagem da dissecação, se concentram sobre o cadáver aberto, a psicanálise vai nos remeter ao olhar, à curiosidade e, sobretudo, à desordem interna que a questão das origens pode causar. Este descentramento é intrínseco à teorização psicanalítica do fantasma da cena primitiva. Em psicanálise, o sujeito vai se fixar não tanto na "cena", mas na atitude interna, induzida nele a partir da cena. O olhar é, neste sentido, direcionado para o interior.

A metáfora do olhar alcança toda sua dimensão quando a conectamos à indexação, feita por Freud, do ver ao saber. Não obstante, devemos compreender esta metáfora do olhar e sua relação com o saber em psicanálise, a partir dos dois seguintes eixos:

- O primeiro, bastante explícito, elaborado desde os "Três ensaios...", situa a pulsão de saber como, de alguma maneira, derivada da pulsão de ver: "A pulsão de saber (...) corresponde, por um lado, ao aspecto sublimado da pulsão de 'controle' e, por outro, trabalha com a energia do prazer escópico". ${ }^{3}$

- O segundo eixo, que atravessa toda a obra freudiana, onde a metáfora do olhar subverte de alguma forma a relação com o visível, transpõe o paradigma da imagem e do figurativo para a cena do sonho. Neste sentido, o tema da visão, que

2. S. Mijolla-Mellor. "De la découverte de Freud à la recherche en psychanalyse", in Topique 61, Paris, Dunod, 1996, p. 483.

3. S. Freud (1905). Trois essais sur la theorie sexuelle. Paris, Gallimard, 1987, p. 123. 


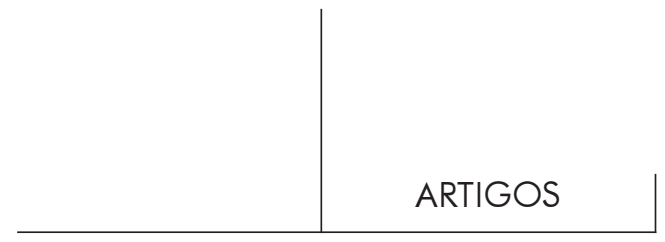

reaparece constantemente em A interpretação dos sonhos, através das figuras do zarolho, do míope, dos olhos feridos... adquire uma outra dimensão.

\section{Primeiro eixo: do ver ao saber}

Se o anatomista do Renascimento se prevaleceu de um objeto que, porque visível, seria assim esvaziado dos seus mistérios, Freud colocou em evidência uma outra posição. Efetivamente, grandes mistérios seriam colocados a partir do visível, que se encontra, em psicanálise, imediatamente vinculado à diferença dos sexos e à castração; o que não deixa de nos evocar o tema mítico da cegueira na tragédia de Édipo.

Mas se a pulsão epistemofílica deriva de alguma forma da pulsão escópica, seria necessário relembrar, mesmo que de maneira breve, do que esta pulsão é feita e pelo que ela é movida. A visão é fonte da pulsão escópica em função da qualidade do estímulo visual, tudo se passando como se, para Freud, o ver só pudesse ser erógeno a partir do momento em que é o órgão genital, e mais precisamente o pênis, que se trata de ver.

O prazer de ver seria induzido pelo olhar que a criança direciona aos seus órgãos genitais que a masturbação fez conhecer como lugar de uma experiência de prazer. ${ }^{4}$ A masturbação seria, assim, o ato iniciador da erogeneidade visual. $\mathrm{O}$ olhar da criança que vem primeiramente redobrar o prazer masturbatório, direcionandose rumo ao órgão genital, volta-se depois para outros órgãos genitais, num objetivo de comparação.

Não obstante, a perspectiva de comparação não se resume ao órgão genital do "companheiro de jogo", do "alter ego", mas se dirige precisamente para o órgão genital da própria mãe. Podemos pensar que o que motiva então o desejo de ver da criança, é "o prazer que ela pode esperar em constatar um suposto pênis na mãe" Este objeto fálico inexistente, o suposto pênis da mãe, só ele seria capaz de proteger a criança contra a angústia de castração.

A emergência da "pulsão de saber" a partir da "pulsão de ver" deve ser compreendida em função do objeto visado por esta última e pela necessidade de controle que está em jogo.

O desejo de ver se prolonga em desejo de saber quando ele visa este objeto ausente, posto que se o saber pode chegar a um resultado, este saber relança sempre um não saber. ${ }^{6}$

4. Idem, p. 120.

5. S. Mellor-Picaut. "La vision et l'enigme", in Topique 25, Paris, EPI, 1980, p. 89.

6. S. Mijolla-Mellor. Psychanalyse. Paris, PUF, collection "Fondamental", 1996, p. 376. 


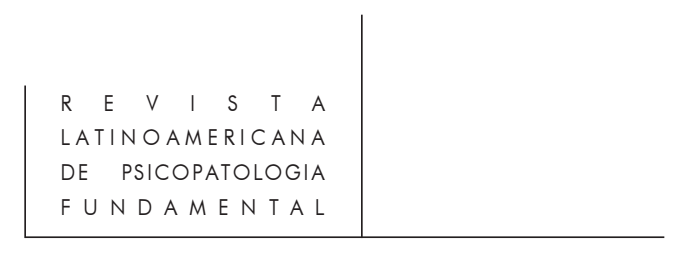

Neste processo, o controle está diretamente em jogo: o que está em questão é tentar assegurar que a fonte do prazer existe e que o sujeito a domina.

Todavia, a pulsão de saber corresponde, além de uma derivação da pulsão escópica, a uma necessidade prática ${ }^{7}$. Esta pulsão egoísta, primeiro móvel da investigação sexual infantil, está, de fato, relacionada com o receio relativo à diminuição dos cuidados que resultaria do possível nascimento de uma nova criança, o que é primeiramente vivido no plano sexual de apego libidinal à mãe.

Portanto, o interesse que leva o "pequeno Édipo" nas suas pesquisas, e que está na base da gênese da pulsão de saber, é também um interesse sexual, mas ele se refere a um bem possuído - o carinho da mãe - e não a uma ausência. O enigma está então vinculado a este momento no qual a ternura da mãe não aparece mais como um dado incondicional, mas como um bem contingente. $\mathrm{O}$ que equivale a dizer que, num primeiro tempo, a pulsão de saber não depende de um desejo de saber ou de controle em geral e erotizado enquanto tal, mas procede precisamente de uma necessidade de saber.

A questão principal que o desejo do "pequeno Édipo" coloca se refere precisamente ao problema de "como conservar o amor da mãe?" Não obstante, a questão que ele vai formular assume uma outra forma: "Como nascem as crianças?". Esta questão vai então remetê-lo não somente ao temido nascimento de um irmãozinho ou irmãzinha, mas também e sobretudo, ao seu próprio nascimento, à sua própria origem. É esta questão que vai ocupar o lugar prototípico do "enigma". Neste sentido, a pulsão de saber vai se constituir secundariamente ao enigma.

Se a pulsão escópica está presente no desejo de saber é porque este depende da figuração da cena primitiva. Mas se ver se prolonga em saber é porque a cena primitiva só se oferece como enigma. A pulsão de saber investe e erotiza a dimensão enigmática.

Poderíamos pensar que é precisamente neste ponto que a referência ao olhar em psicanálise se destaca radicalmente da idéia de objetivação, ligada ao ver, presente nas ciências modernas. Se assistimos em Freud, tal como nas ciências ocidentais, a uma indexação do ver ao saber, devemos admitir que o ver em psicanálise nos remete primordialmente ao que não se entrega à vista. A cena primitiva, as imagens do sonho, as lembranças encobridoras, o sintoma histérico são apenas figurações metafóricas; imagens que, mesmo sendo visuais, não são necessariamente visíveis.

7. S. Freud. (1905). Trois essais sur la theorie sexuelle. Op. cit., p. 123. 


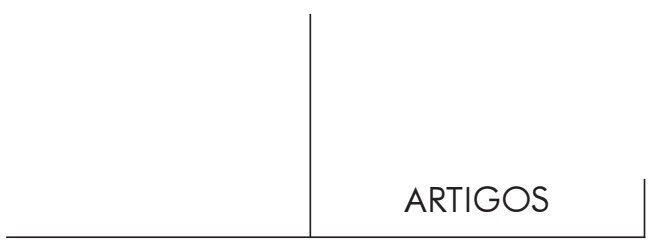

Segundo eixo: a cena do sonho

O paradigma do sonho, do sintoma histérico, subverte de certo modo o lugar do "ver" na psicanálise. Se a imagem de A lição de anatomia pode figurar de alguma maneira como a "cena primitiva" das ciências médicas, a imagem emblemática do nascimento da psicanálise é a do sonho, a do sonho de Irma:

Então ela abre bem a boca, e eu constato à direita uma grande mancha branca, e além disso eu percebo extraordinárias formações cutâneas que têm a aparência de cornetas do nariz, e sobre elas grandes escarros branco-grisalhos. Eu chamo imediatamente o Dr M. ${ }^{8}$

É interessante destacar aqui que a cena descrita pode lembrar A lição de anatomia. Estas duas cenas representam médicos que observam e classificam; todavia, uma se apresenta aos olhos tal uma "natureza morta", enquanto a outra é contada e interpretada. Assim, o relato deste sonho nos remete a algo bem distinto de A lição de anatomia. A garganta aberta de Irma só se deixa ver com os olhos fechados. Nós todos a lemos e a relemos, mas nunca a vimos, por assim dizer. A cena se relata e o figurativo está nas palavras. Este sonho e sua interpretação fundaram de alguma maneira a psicanálise e consagraram ao sonho um lugar paradigmático na teoria e na técnica psicanalítica. $\mathrm{O}$ visual se encontra doravante nas entranhas da metáfora, se aproximando de um enigma a ser decifrado pelas palavras, do mesmo modo que o sintoma histérico.

Já podemos pressentir o lugar que a palavra vai ocupar em psicanálise. "Efetivamente a referência ao paradigma do sonho faz do ato de escutar em psicanálise um ato de linguagem"9 .

Se o renascimento se apegou ao visível, acalmando as dúvidas e os demônios da subjetividade, a psicanálise vai atribuir à palavra um caráter figurativo, esclarecedor:

Uma criança ansiosa, por estar no escuro, se dirige à sua tia que se encontra no quarto ao lado: — "Tia, fala comigo, eu estou com medo." — "De que isso vai adiantar, já que você não me vê?" Ao que a criança responde: — "Fica mais claro, quando alguém fala."10

8. S. Freud (1900). L'interpretation des rêves. Paris, PUF, 1993, p. 100.

9. P. Fédida. Crise et contre transfert. Paris, PUF, 1992, p. 55.

10. S. Freud. (1916-1917). "L'angoisse", in Introduction à la psychanalyse. Paris, Payot, 1961, p. 384 ( itálicos meus). 


\section{Pesquisa e psicanálise}

Pulsão de saber e enigma são também forças motrizes, suscetíveis de lançar o sujeito nesta singular pesquisa, que é a cura psicanalítica. Pesquisa e psicanálise estão a tal ponto entrelaçadas que Winnicott postula que todo clínico é um pesquisador, a cura sendo, de alguma forma, uma pesquisa inesgotável do material recalcado.

Para apreender a especificidade do trabalho psicanalítico, Freud vai falar de uma aceitação do recalque (...) No entanto, se encontra subvertida a conexão feita antes, nos "Três ensaios...": conexão entre pulsão de saber e pulsão escópica. A aceitação do recalque só é possível a partir de uma ferida infligida à "paixão escópica" "11. O olhar, então voltado para o interior, consagra os sonhos como vias reais de acesso ao inconsciente, ao infantil. O método de investigação, descoberto através do sonho, segue o fio de um processo interno: o recalque.

Este olhar voltado para o interior esboça uma diferença fundamental entre o visual e o visível. Se podemos e devemos relembrar que a psicanálise se ocupa do visual e do figurativo (sonho, sintoma), a diferença com o visível deve ser marcada. De fato, para deixar advir a "revolução galileana da cena psíquica" devemos de certa forma renunciar às ilusões do visível e do sensível.

Se a relação ao visível marca um ponto de ruptura da psicanálise com as ciências ocidentais (particularmente daquelas derivadas das ciências anatômicas), esta ruptura nos remete a muitas outras rupturas que dizem respeito, principalmente, à relação entre o observador e o seu objeto. O silêncio cadavérico é substituído, em psicanálise, pela escuta de uma palavra viva, e, mais ainda, de uma palavra surpreendente. A escuta se dirige para uma palavra que não sabia o que ela tinha a dizer. O "controle" é colocado em questão não somente do lado do analisando, mas também do lado do analista. Nesta configuração, o que a ciência moderna tanto quis evacuar - a subjetividade - se transformou, com o gênio de Freud, no trunfo da psicanálise, no seu instrumento de trabalho. $\mathrm{O}$ analista opera com a transferência, esse elo que liga analista e analisando.

Convém, todavia, destacar, ainda mais uma vez, que a subversão do sentido da "observação", em psicanálise, é diretamente conectada com as noções de transferência e contratransferência. $O$ analista não observa somente um objeto externo, mas também e, principalmente, a maneira como este objeto ressoa nele. $\mathrm{O}$ "olhar voltado para o interior" diz respeito não somente ao analisando ou ao objeto de estudo, mas também ao analista que vai escutar e trabalhar a partir do seu

11. M. Schneider. "Le franchissement du seuil. Freud et la thématique du regard", in Cliniques Méditérranéennes $\mathrm{n}^{\mathrm{o}}$ 51/52, Érès, 1996, p. 29. 


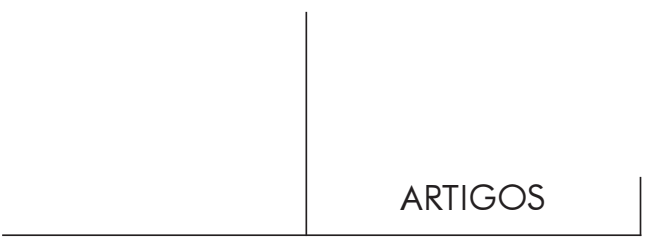

inconsciente e da sua realidade infantil. A contratransferência funciona de alguma maneira como o "princípio de relatividade"12, que não se deve desconhecer, mas que, por outro lado, não se trata de eliminar, posto que os elos transferenciais são os instrumentos princeps do trabalho psicanalítico.

\section{A pesquisa em psicanálise}

Se a cura e a clínica psicanalíticas constituem, por elas mesmas, um certo tipo de pesquisa, resta ainda precisar seus vínculos com a dita "pesquisa científica" e as especificidades do que poderíamos chamar de "pesquisa em psicanálise". O trabalho analítico é, de alguma maneira, pesquisa inesgotável do reprimido e do infantil, onde transferência e contratransferência são os instrumentos de investigação. Se o sonho é o paradigma da teoria e da técnica psicanalítica, não se deve esquecer que "é transferencialmente que o sonho se relembra e fala"13.

Este elo que, na clínica psicanalítica, liga analista e analisando, deve nos questionar sobre o elo que, numa pesquisa, liga o pesquisador ao seu objeto de investigação. Neste sentido, a escolha do tema de trabalho e da teoria para explorálo, nunca é insignificante.

O ângulo de leitura (que chamamos teoria) preside o sentido do recorte, mas também é, por outro lado, algo do elo transferencial que liga o observador ao seu objeto de investigação. ${ }^{14}$

No que diz respeito ao objeto de estudo, ele só pode estar em ressonância com uma problemática pessoal, seja qual for a "vestimenta" teórica e metafórica sob a qual ele for apresentado. Esta dimensão não deve ser desconhecida, sob o risco de retornar na forma de uma inibição. Neste sentido, o objeto científico funcionaria como uma construção que interage, "sob um modo defensivo ou sublimatório, com o conflito inconsciente do observador". ${ }^{15}$ Teorização, vale dizer, secundarização do pensamento, e problemática conflitual inconsciente do teórico são intimamente entrelaçadas e não param de se estimular uma à outra.

12. Idéia de Georges Devreux citada por Isabelle Lasvergnas, "Le corps mort de la pensée ou l'irreductible altérité de la méthode psychanalytique", in Voies de la recherche en psychanalyse. Toulouse, P.U. Mirail, 1992, p. 92.

13. P. Fédida. Op. cit., p. 50.

14. I. Lasvergnas. "Le corps mort de la pensée ou l'irreductible altérité de la méthode psychanalytique", in Voies de la recherche en psychanalyse, op. cit., p. 87.

15. Idem. 


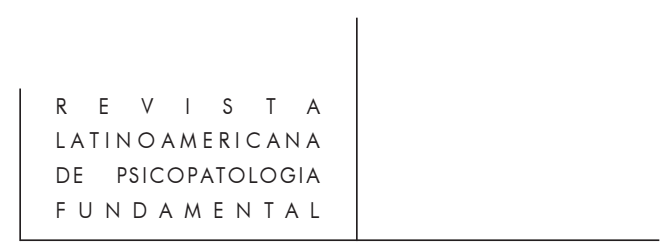

Nesta perspectiva, todo trabalho de pesquisa, qualquer que seja o domínio, é também, uma autoconstrução do seu autor. Todavia, não podemos ignorar que esta dimensão é multiplicada quando se trata de uma pesquisa em psicanálise.

A pesquisa como busca de saber, elaboração secundarizada, tentativa de controle de um assunto de interesse "eleito" não deve estar relacionado com a famosa "zona cega", com os restos "não analisados", que no analista relançam ao infinito a sua própria análise? Como os famosos "casos de análise" que seriam para o analista "potentes motores de análise sem 'fim', a partir deste lugar do 'outro', produtor de 'auto'-análise". ${ }^{16}$

Como bem lembram P. Fédida e P. Lacoste, a teoria psicanalítica nasceu da patologia:

... como nenhuma outra teoria, ela se enriqueceu e se propagou a partir dos desencadeamentos progressivos e sucessivos dos teóricos e de suas próprias patologias, se analisando uns aos outros - o que continua o princípio da formação de psicanalistas..." ${ }^{17}$

O fato de a clínica psicanalítica estar no centro da transmissão da psicanálise multiplica as razões para não negligenciar as relações entre teoria e transferência.

Se na clínica psicanalítica o movimento contratransferencial do analista é, primeiramente e antes de mais nada, uma resposta em simetria à transferência do analisando, não devemos compreender, como propõe Isabelle Lasvergnas, a elaboração metapsicológica como uma produção de um objeto fictício, ajudando o analista a se distinguir um pouco da confusão primeira, em jogo na contratransferência? Neste sentido, os seminários clínicos, as histórias de caso e as supervisões são de alguma maneira nutridos deste objeto fictício. A pesquisa em psicanálise, tão científica quanto ela possa se pretender, não saberia se poupar desta dose de ficção.

O trabalho principal da formulação e do recentramento do objeto de pesquisa vai ser o de constituir, com a ajuda de balizas teóricas, uma "área transicional" no interior da qual, o íntimo que o tema escolhido se faz portador, possa ser metabolizado em pesquisa comunicável. A elaboração desta "área transicional" nos evoca sem demora o phantasieren ${ }^{18}$ metapsicológico de Freud. Mesmo considerando

16. P. Fédida. "La construction du cas", in Nouvelle revue de psychanalyse, $\mathrm{n}^{0} 42$, Paris, Gallimard, 1990, p. 246.

17. P. Fédida e P. Lacoste. "Psychopathologie/ Métapsychologie, la fonction des points de vue", in Revue Internationale de Psychopathologie, $\mathrm{n}^{0}$ 8, 1992, p. 600.

18. "Sans spéculer ni théoriser - pour peu j'aurais dit fantasmer - metapsychologiquement on návance pas ici d'un pas". cf. S. Freud (1937). "Analyse avec fin, analyse sans fin”, in Résultats, idées, problèmes II. Paris, PUF, 1992, p. 240. ( itálicos meus) 


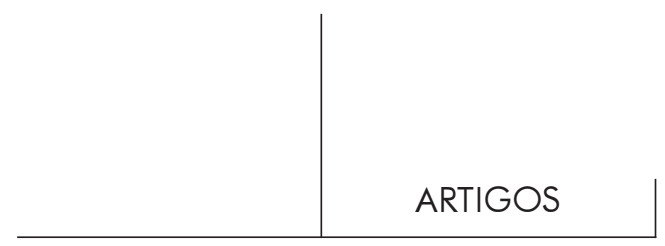

que o trabalho de pesquisa tem raízes pulsionais (relacionadas com a pulsão de saber e não somente com um prazer ou uma vontade), em ciência não se trataria de ceder à pulsão, o que exporia o pesquisador ao recalque e à inibição, mas sim de metabolizar essas raízes pulsionais com a ajuda da ficção e do movimento sublimatório. Efetivamente, fantasma e ficção sustentam o desejo, economizando um pouco as contas do recalque, e se orientando assim rumo a uma solução sublimatória.

A derivação sublimatória cobre um campo considerável, correspondendo tanto à pulsão de saber quanto ao prazer estético diante de uma obra de arte (o que nos traz de novo, de alguma forma, ao olhar e à visão...). Todavia, o que marca tanto a continuidade como a ruptura da sublimação, no interior da pulsão escópica, é uma troca de objeto pulsional. O objeto da sublimação não é mais um objeto fálico, mas, de alguma forma, o escancaramento da castração tal como a criança a vislumbra na cena primitiva ${ }^{19}$. O mecanismo sublimatório implica na capacidade não somente de reconhecer a ausência do objeto, mas de aceitar tanto um saber sobre o caráter definitivo desta ausência como de uma busca, não do objeto ou de um substituto, mas da causa da ausência e do sofrimento que ela provoca.

Para não concluir

A psicanálise como "ciência fundada na observação" ${ }^{20}$, deslocou o sentido da "observação" de sua relação com o visível. Não se distanciando nunca para uma especulação sem vínculos com a clínica, Freud operou um remanejamento na noção de "observação". O objeto não é mais o "visível" e a "observação" não é mais uma constatação. A verdade é sempre relativa, relativa à transferência. Freud efetivamente "venceu onde o paranóico fracassa". Renunciando à busca da verdade absoluta, e às sínteses conclusivas, o olhar em psicanálise escapa à sua dimensão paranóica, ao "mau olhado".

A pesquisa em psicanálise, à imagem de sua clínica, só pode pretender a produção de "verdades relativas", de "construções operantes". Construções, algo fictícias, mas suscetíveis de trazer novos pensamentos e novas capacidades de escuta na clínica psicanalítica.

19. S. Mellor-Picaut. "La vision et l'énigme”, op. cit., p. 108.

20. S. Freud (1925). Sigmund Freud présenté par lui même. Paris, Gallimard, 1984, p. 98. 


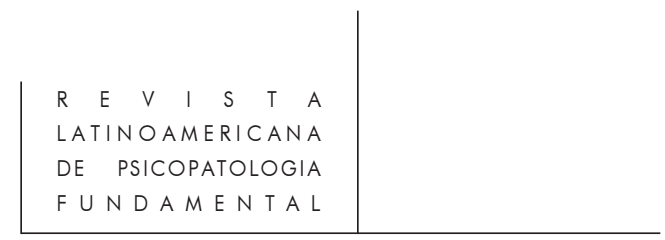

\section{Resumos}

Partiendo de la imagen de la disección de cadáveres, considerada como "escena primitiva" de la ciencia moderna, el presente artículo se propone indicar una especificidad de la observación en psicoanálisis a través del paradigma del sueño, espacio, que no corresponde más a lo visible, sino a lo visual y alucinatorio. Dentro de esta configuración, la observación se encuentra intrínsecamente ligada a la experiencia transferencial. La autora señala, entonces, los lazos transferenciales que ligan investigador y objeto de estudio, en una analogia entre la investigación científica y la situation analítica.

Palabras-llave: Observación, sueño, transferencia, psicoanálisis.

Partant de l'image de la dissection des cadavres, envisagée comme "scène primitive" de la science moderne, cet article se propose d'indiquer une spécificité de l'observation en psychanalyse au travers du paradigme du rêve, espace, non plus du visible, mais du visuel et de l'hallucinatoire. Dans cette configuration, l'observation se trouve intrinsèquement liée à l'expérience transférentielle. L'auteur relève donc les liens transférentiels qui lient chercheur et objet d'étude dans une analogie entre l'investigation scientifique et la situation analytique.

96 Mots-clef: Observation, rêve, transference, psychanalyse.

By beginning with the image of the dissection of cadavers, considered as "primal scene" of modern science, this article proposes to point to a specificity of the observation in psychoanalysis through the paradigm of the dream, no more a visible territory, but a visual and hallucinatory one. In this configuration, the observation finds itself intrinsically linked with the experience of transference. The author then points to the transferencial links which join the researcher to his object of study, by establishing an analogy between scientific investigation and the analytic situation.

Key words: Observation, dream, transference, psychoanalysis. 